\title{
Studies on electrical double layer capacitor with a low-viscosity ionic liquid 1-ethyl-3-methylimidazolium tetracyanoborate as electrolyte
}

\author{
G P PANDE $Y^{1}$ and S A HASHMI* \\ Department of Physics and Astrophysics, University of Delhi, Delhi 110 007, India \\ ${ }^{1}$ Present address: Center for Autonomous Solar Power (CASP), Binghamton University, State University of New York, \\ Binghamton, NY 13902, USA
}

MS received 4 October 2011; revised 22 November 2012

\begin{abstract}
The performance of an electrical double layer capacitor (EDLC) composed of high surface area activated carbon electrodes and a new ionic liquid, 1-ethyl-3-methylimidazolium tetracyanoborate, [EMIm]TCB, as the electrolyte has been investigated by impedance spectroscopy, cyclic voltammetry and galvanostatic charge-discharge studies. The high ionic conductivity $\left(\sim 1.3 \times 10^{-2} \mathrm{~S} \mathrm{~cm}^{-1}\right.$ at $\left.20^{\circ} \mathrm{C}\right)$ and low viscosity $(\sim 22 \mathrm{cP})$ of the ionic liquid, [EMIm]TCB, make it attractive as electrolyte for its use in EDLCs. The optimum capacitance value of $195.5 \mathrm{~F} \mathrm{~g}^{-1}$ of activated carbon has been achieved with stable cyclic performance.
\end{abstract}

Keywords. Ionic liquid; activated carbon; electrical double layer capacitor; cyclic voltammetry; impedance spectroscopy.

\section{Introduction}

Electrochemical double layer capacitors (EDLCs), also known as supercapacitors, are the intermediate devices between electrochemical batteries that can store high energy and dielectric capacitors, which can deliver very high power in a few ms (Conway 1999; Kötz and Carlen 2000; Simon and Gogotsi 2008). These are widely used in the fields of mobile communication, aviation and information technology, etc. Since the electric energy stored in EDLCs are raised by the accumulation of charged species at the electric double layers, i.e. at the interface between a polarizable electrode and an electrolyte, the performance of EDLCs depend strongly on both the electrolyte and characteristics of used carbon material as electrodes (Conway 1999; Frackowiak and Beguin 2001; Hashmi 2004).

Currently, the employed electrolytes in commercial supercapacitors include aqueous and organic electrolytes (Duong 2003). Most of the EDLCs use aqueous solution electrolytes for good conductivity, however, narrow electrochemical window $(\sim 1.2 \mathrm{~V})$ leads to low values of cell voltage, which largely limit both energy and power density values of these devices. EDLCs with organic electrolytes, having operational voltage $\sim 2.5-2.7 \mathrm{~V}$, possess higher energy and power densities, which are acceptable for many applications. But, these organic electrolytes suffer from serious safety problems as they are inherently volatile, flammable and toxic, resulting in a narrow operational temperature range (Simon and Gogotsi 2008).

\footnotetext{
*Author for correspondence (sahashmi@physics.du.ac.in)
}

In recent years, room temperature ionic liquids (RTILs) have attracted wide attention as the electrolytes for electrochemical devices including rechargeable batteries, supercapacitors, fuel cells, etc (Sato et al 2004; Ohno 2005; Ye et al 2007; Armand et al 2009; Mysyk et al 2010). The properties of ionic liquids, which make them solvent-free "green" electrolytes include non-volatility, non-flammability, high ionic conductivity, wider electrochemical potential window, high chemical and thermal stability. Recently, some ionic liquids based EDLCs are reported with different carbon electrodes (Lewandowski and Galinski 2004; Xu et al 2006; Balducci et al 2007; Lu et al 2009), however, their practical application has often been limited by their high viscosity at ambient temperature. The viscosity of ionic liquid such as [EMIm] $\mathrm{BF}_{4}$ (Sun et al 2006), [BMIm] $\mathrm{BF}_{4}$ (Sun et al 2006) and [EMIm]TFSI (Handa et al 2008), which are frequently used as electrolytes of EDLCs, are 37.7, 233 and $28 \mathrm{cP}$, respectively. These values are much higher than that of aqueous and organic electrolytes, which result in the increase of internal resistance $(R)$, one of the most important factors for EDLCs performance characteristics. It may be noted that for high power output capability, internal resistance of the devices should be as low as possible. Recently, low viscous hydrophobic ionic liquid, 1-ethyl-3-methylimidazolium tetracyanoborate ([EMIm]TCB) has been examined for various electrochemical applications (Shi et al 2008; Rotariu et al 2010; Yan et al 2010). Grätzel and coworkers (Kuang et al 2006) used this tetracyanoborate ionic liquid electrolyte for dye-sensitized solar cells (DSSCs) applications.

The present paper reports our latest investigation on EDLCs based on high conductivity and low viscosity ionic liquid, [EMIm]TCB as the electrolyte, without using any 
other common solvent as diluents and activated carbon as an electrode material. The capacitors have been characterized using impedance spectroscopy, cyclic voltammetry $(\mathrm{CV})$ and charge-discharge studies.

\section{Experimental}

The ionic liquid, 1-ethyl-3-methylimidazolium tetracyanoborate, [EMIm] TCB was obtained from Merck, Germany and dried at $\sim 80^{\circ} \mathrm{C}$ in a vacuum oven before use. The electrochemical window of [EMIm] TCB, soaked in porous glass microfibre separator, was measured by linear sweep voltammetry (LSV) using stainless steel as working electrode and $\mathrm{Ag}$ foil as combined counter and reference electrodes. Commercially activated carbon (YEC-8, Fuzhou Carbon Co., China) was used as electrode material. The carbon powder was dried in a vacuum oven overnight at $\sim 100{ }^{\circ} \mathrm{C}$ before use. Porous texture of the activated carbon was analysed by $\mathrm{N}_{2}$ adsorption at $77 \mathrm{~K}$ using surface area and pore size analyser (Micromeritics-Gemini-V). BET specific surface area was found to be $\sim 2180 \mathrm{~m}^{2} \mathrm{~g}^{-1}$.

To prepare electrodes for EDLC application, the composition of activated carbon, acetylene black and poly(vinylidenefluoride-hexafluoropropylene) (PVDF-HFP) as a binder with a ratio of 80:10:10 (w/w) was mixed in a mortar and pestle to form a slurry in acetone. This slurry was coated on high density graphite sheets $(25 \mu$ m thick, FMI Composite Ltd.). The prepared electrodes were vacuumdried overnight at $\sim 100{ }^{\circ} \mathrm{C}$ before fabricating EDLC cells. Symmetrical cells of EDLCs with two identical carbon electrodes were assembled in specifically designed sample holders using porous glass microfibre separator, soaked with ionic liquid.

The performance characteristics of EDLC cells were evaluated using a.c. impedance spectroscopy, cyclic voltammetry and galvanostatic charge-discharge studies. A.C. impedance spectroscopy of the capacitor cells was carried out in the frequency range from $10 \mathrm{mHz}$ to $100 \mathrm{kHz}$ at a signal level of $20 \mathrm{mV}$ using the electrochemical analyser (model 608C, CH Instruments). The overall capacitances $(C)$ of EDLC cells were evaluated using the expression:

$$
C=\frac{-1}{\omega \cdot Z^{\prime \prime}},
$$

where $\omega$ is the angular frequency and $Z^{\prime \prime}$ the imaginary part of the total complex impedance $Z$. Single electrode specific capacitance values were evaluated by multiplying the overall capacitance by a factor of two and dividing by the mass of the single electrode material.

Cyclic voltammetry was performed with the help of electrochemical analyser, mentioned above. The capacitance values were evaluated using the relation:

$$
C=\frac{i}{s}
$$

where $i$ is the current and $s$ the scan rate. The chargedischarge characteristics of the capacitor cells were evaluated at constant currents using charge-discharge unit (model: BT2000, Arbin Instrument, USA). The discharge capacitance ' $C$ ' was evaluated from the linear part of the discharge curves using the relation:

$$
C_{\mathrm{d}}=\frac{i \cdot \Delta t}{\Delta V}
$$

where $i$ is the constant current and $\Delta t$ the time interval for the voltage change of $\Delta V$. Coulombic efficiency $(\eta)$ was calculated using the following equation:

$$
\eta=\frac{t_{\mathrm{d}}}{t_{\mathrm{c}}} \times 100 \%
$$

where $t_{\mathrm{d}}$ and $t_{\mathrm{c}}$ are the times for galvanostatic discharging and charging, respectively.

\section{Results and discussion}

\subsection{Properties of ionic liquid}

[EMIm]TCB is a relatively new ionic liquid which offers low viscosity, high conductivity and high chemical and thermal stability (Welz-Biermann et al 2004). Table 1 presents a comparison of some physical properties of a few important ionic liquids and an organic electrolyte commonly used for EDLC applications. The electrochemical window of the electrolytes is an important parameter to be evaluated from their application point of view in electrochemical devices such as supercapacitors, etc. The electrochemical potential window of the present ionic liquid, [EMIm]TCB was tested by LSV using a cell: SS $|\mathrm{IL}| \mathrm{Ag}$. Figure 1 shows linear sweep voltammogram of the present ionic liquid electrolyte. The ionic liquid [EMIm]TCB shows electrochemical stability up to $\sim 4.0 \mathrm{~V}$,

\begin{tabular}{|c|c|c|c|c|}
\hline & Viscosity at RT (cP) & Conductivity $\left(\mathrm{S} \mathrm{cm}^{-1}\right)$ & $\begin{array}{l}\text { Electrochemical } \\
\text { window }(\mathrm{V})\end{array}$ & References \\
\hline $\mathrm{TEMABF}_{4} / \mathrm{PC}$ & $4 \cdot 2$ & $1.5 \times 10^{-2}$ & $2 \cdot 7$ & Handa et al (2008) \\
\hline$\left[\mathrm{EMIm}_{\mathrm{B}} \mathrm{BF}_{4}\right.$ & $37 \cdot 7$ & $2 \cdot 3 \times 10^{-3}$ & $4 \cdot 2$ & McEwen et al (1999) \\
\hline [EMIm]TFSI & 28 & $8.4 \times 10^{-3}$ & $4 \cdot 1$ & McEwen et al (1999) \\
\hline [EMIm]TCB & 22 & $1.3 \times 10^{-2}$ & $4 \cdot 0$ & $\begin{array}{l}\text { Welz-Biermann et al (2004) } \\
\text { (Present study) }\end{array}$ \\
\hline
\end{tabular}
which is an acceptable working voltage range from EDLC application point of view.

Table 1. Comparative characteristics of various liquid electrolytes. 


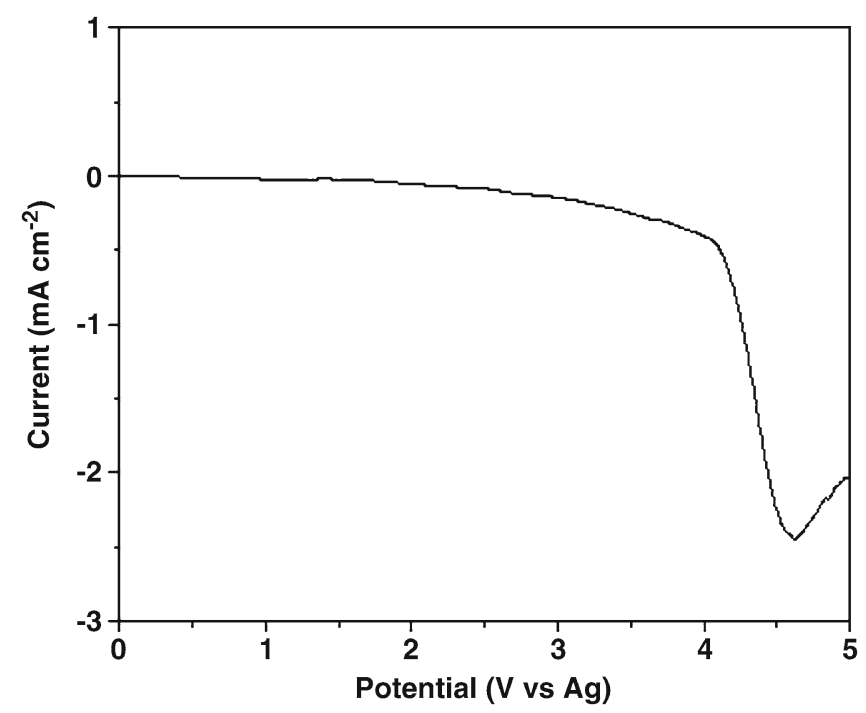

Figure 1. Linear sweep voltammogram of ionic liquid, [EMIm] TCB electrolyte using SS $|\mathrm{IL}| \mathrm{Ag}$ cell; scan rate is $2 \mathrm{mV} \mathrm{s}^{-1}$.
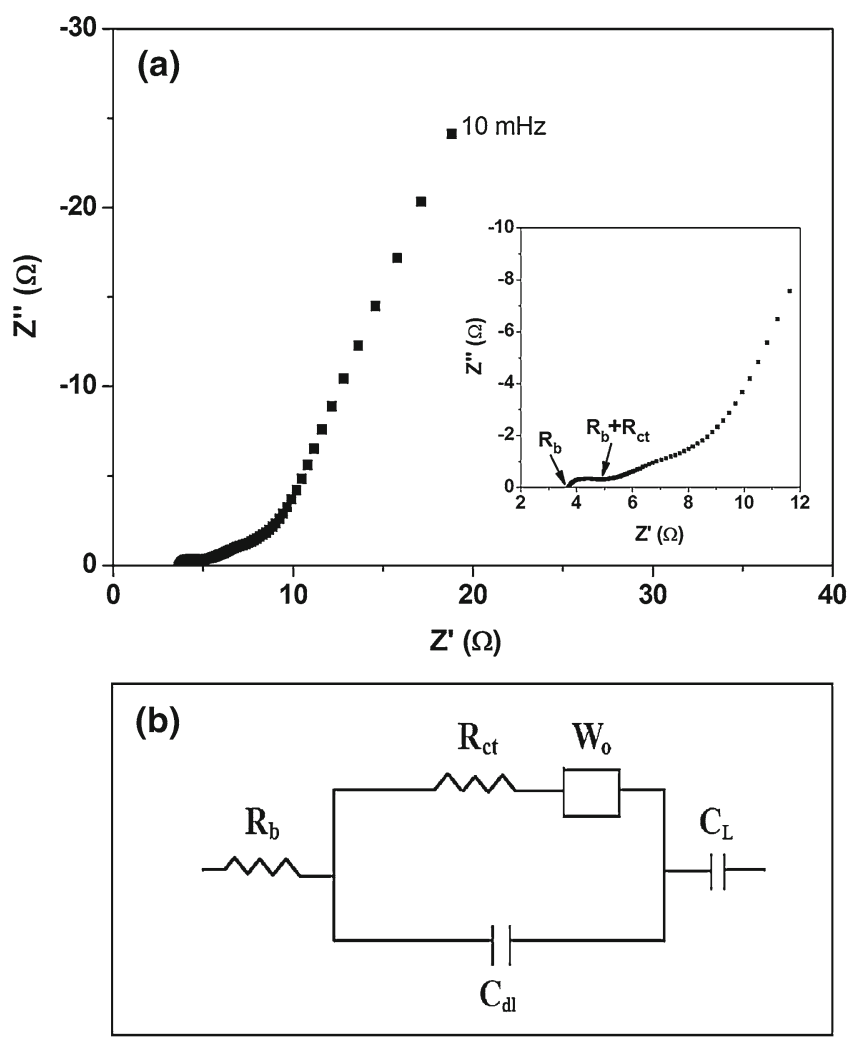

Figure 2. Typical impedance plot of EDLC cell, recorded at room temperature in frequency range from $100 \mathrm{kHz}$ to $10 \mathrm{MHz}$. Expanded curve in high frequency region is shown in inset.

\subsection{Performance studies of EDLCs}

Figure 2 shows typical impedance spectra of EDLC cell. The activated carbon electrode (being highly conducting, larger specific surface area and porous material) shows a capacitive behaviour with the ionic liquid, [EMIm]TCB, as

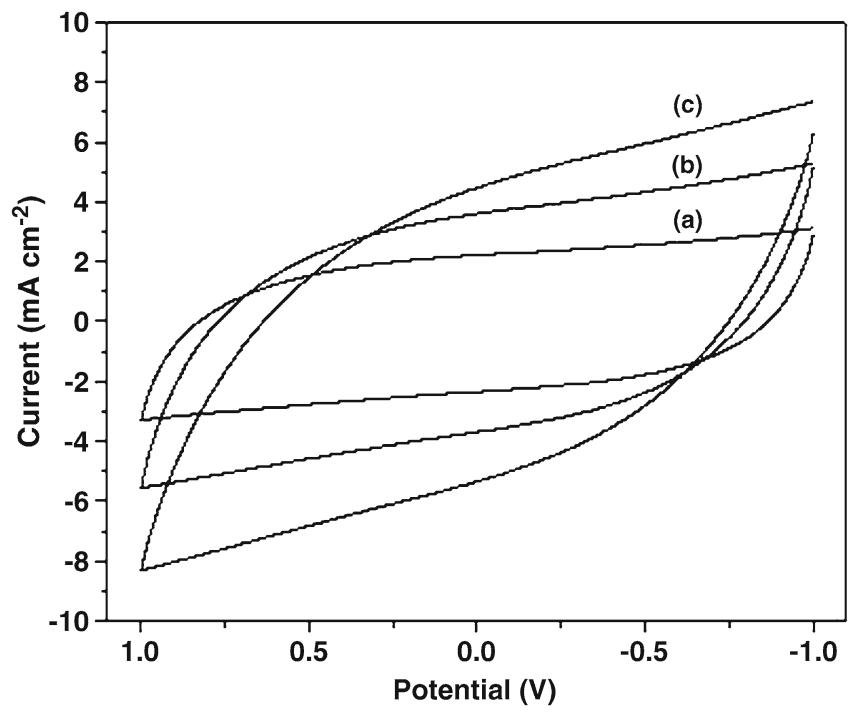

Figure 3. Cyclic voltammograms of EDLC cell at different scan rates: (a) $5 \mathrm{mV} \mathrm{s}^{-1}$, (b) $10 \mathrm{mV} \mathrm{s}^{-1}$ and (c) $20 \mathrm{mV} \mathrm{s}^{-1}$ recorded at room temperature.

reflected by the steep rising behaviour of the impedance plot in the lower frequency range. It should be noted that the ideal impedance behaviour of a pure capacitor is a straight line parallel to the imaginary axis $\left(Z^{\prime \prime}\right)$, whereas in practical capacitors, the steep rising capacitive impedance response is observed in the low frequency region accompanied with high frequency semicircular features, owing to the bulk and interfacial properties of the capacitor cells. The expanded part of the impedance response at higher frequencies (figure 2 inset) reflects the bulk properties of electrolytes and charge transfer process at electrode-electrolyte interfaces. The values of bulk resistance $\left(R_{\mathrm{b}}\right)$ and interfacial charge-transfer resistance $\left(R_{\mathrm{ct}}\right)$ of EDLC cell could be easily evaluated from the intercepts on the real axis of the impedance response. These resistance values along with the capacitance values evaluated from (1) at the frequency of $10 \mathrm{mHz}$, are listed in table 2. EDLC cell offers a good capacitance value of $440 \mathrm{mF} \mathrm{cm} \mathrm{cm}^{-2}$ which is equivalent to a single electrode capacitance value of $195.5 \mathrm{~F} \mathrm{~g} \mathrm{~g}^{-1}$. Taking into account the maximum surface of the activated carbon $\left(\sim 2180 \mathrm{~m}^{2} \mathrm{~g}^{-1}\right)$, specific capacity of carbon/electrolyte interface is $\sim 11 \mu \mathrm{F} \mathrm{cm}^{-2}$.

Nyquist plot of EDLC cell can be represented by a modified Randle's circuit (Wang and Teng 2007), as shown in figure 2(b). High frequency region, represented by the suppressed semicircle, provides combined effect of the bulk resistance of the electrolyte and the internal resistance of electrode represented by $R_{\mathrm{b}}$. The semicircle in high- to midfrequency region is represented by a parallel combination of charge-transfer resistance $\left(R_{\mathrm{ct}}\right)$ and double layer capacitance $\left(C_{\mathrm{dl}}\right)$. The $45^{\circ}$ sloped portion of Nyquist plot, represented by Warburg resistance is associated with the diffusion process of ions at the electrode-electrolyte interfacial region (Wang and Teng 2007). 
Cyclic voltammetric curves obtained at different scan rates have been compared in figure 3 . It appears that the contribution of equivalent series resistance (ESR) (Sun et al 2006) increases with the increase in voltage scan rates, as indicated by the gradual distortion of the $\mathrm{CV}$ curves, which normally display a nearly rectangular shape for a capacitor. However,

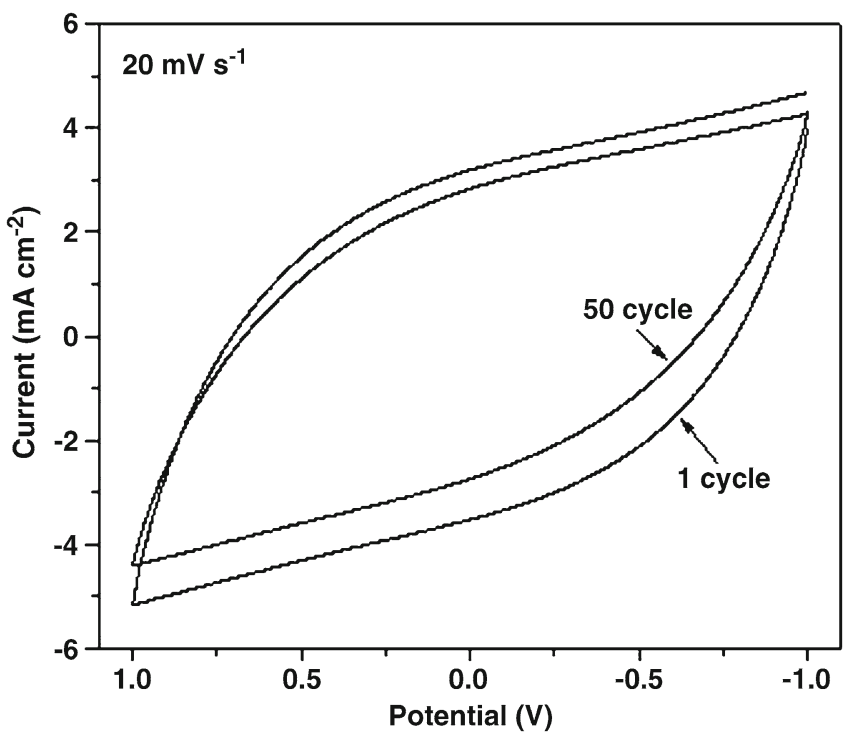

Figure 4. Cyclic voltammograms (1st and 50th cycles) of EDLC cell at a scan rate of $20 \mathrm{mV} \mathrm{s}^{-1}$ recorded at room temperature.

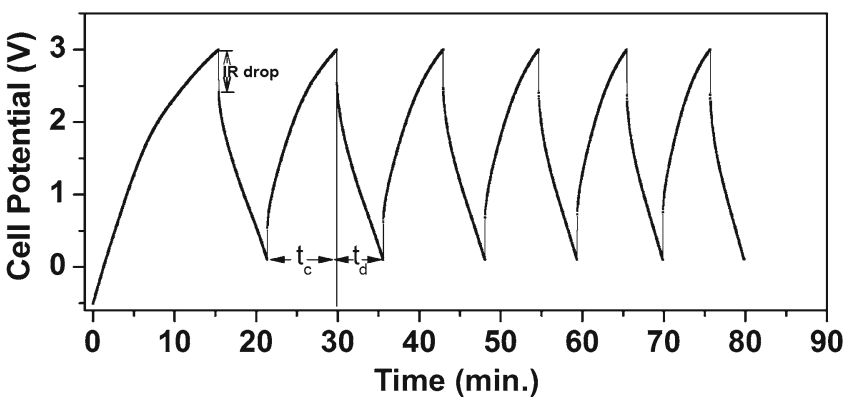

Figure 5. Galvanostatic charge-discharge characteristics of EDLC cell at a constant current of $5 \mathrm{~mA} \mathrm{~cm}^{-2}$. this became significant only when the scan rate was increased to $20 \mathrm{mV} \mathrm{s}^{-1}$. CV curves for EDLC cell at a scan rate of $20 \mathrm{mV} \mathrm{s}^{-1}$ for the 1st and 50th cycles at room temperature are shown in figure 4. Almost featureless characteristics of voltammograms indicate that the electron transfer between the electrode and ionic liquid electrolyte occurs at a constant rate, giving a fairly perfect mirror between charging and discharging process. Capacitance values for EDLC cell, calculated from the capacitive currents and scan rate using (2), agree well with the values obtained from impedance response of the cell.

Figure 5 represents results from initial few consecutive charge-discharge cycles conducted for EDLC at a constant current of $5 \mathrm{~mA} \mathrm{~cm}{ }^{-2}$. EDLC cell was charged from 0 to $3.0 \mathrm{~V}$ at room temperature $\left(20^{\circ} \mathrm{C}\right)$. The wellreproduced charge/discharge cycles, in terms of both charge/discharge time and shape of each individual cyclic curve, strongly suggests an excellent electrochemical stability of this capacitor. However, it is noteworthy that an initial sudden jump/drop in the voltage, while charging and discharging of the capacitor cell, has been observed, which is due to the ohmic loss across the internal resistance $\left(R_{\mathrm{i}}\right.$, also referred as ESR) of the cell. ESR is the combined effect of various types of resistances associated with the intrinsic electronic properties of the electrode material and electrolyte solution, mass transfer resistance of ions in porous carbon matrix and contact resistance between current collector and electrode (Zhang and Zhao 2009). The discharge capacitance $\left(C_{\mathrm{d}}\right)$ value has been evaluated from the linear part of discharge characteristic using (3). The typical value of the discharge capacitance $\left(C_{\mathrm{d}}\right)$ value of EDLC cell, evaluated at a current density of $5.0 \mathrm{~mA} \mathrm{~cm}{ }^{-2}$, has been found to be $\sim 173 \mathrm{~F} \mathrm{~g}^{-1}$ (calculated for second cycle) of the activated carbon. The capacitance value observed from chargedischarge method is comparable with the values obtained from the impedance studies (table 2) and to some extent with the values observed from CV studies. Further, the specific capacitance value, observed by us with the present system, is appreciably larger as compared to the reported values in literature with activated carbon electrodes and neat ionic liquid electrolytes (Lewandowski and Galinski 2004). High value of specific capacitance is owing to the low viscosity of the ionic liquid electrolyte. The less viscous electrolytes have ability to access the porosity of the electrodes for a larger extent and hence, the larger capacitance values are expected.

Columbic efficiency $(\eta)$ has been calculated from the cell using (4). It can be noted that charge-discharge efficiency

Table 2. Electrical parameters of EDLC from impedance analysis.

\begin{tabular}{lcccc}
\hline & $\begin{array}{c}R_{\mathrm{b}} \\
\left(\Omega \mathrm{cm}^{2}\right)\end{array}$ & $\begin{array}{c}R_{\mathrm{ct}} \\
\left(\Omega \mathrm{cm}^{2}\right)\end{array}$ & $\begin{array}{c}C \\
\left(\mathrm{mF} \mathrm{cm}^{-2}\right)^{\mathrm{a}}\end{array}$ & $\begin{array}{c}C \\
\left(\mathrm{~F} \mathrm{~g}^{-1}\right)^{\mathrm{b}}\end{array}$ \\
\hline EDLC cell & 5.5 & 1.7 & 440 & $195 \cdot 5$ \\
\hline
\end{tabular}

${ }^{\mathrm{a} O v e r a l l ~ c a p a c i t a n c e}$ of cell at $10 \mathrm{mHz}$ and ${ }^{\mathrm{b}}$ single electrode capacitance at $10 \mathrm{mHz}$. 
gradually increases from $\sim 75 \%$ in first cycle to $\sim 87 \%$ after initial few cycles. This indicates the interfacial stability between electrode and ionic liquid electrolyte.

\section{Conclusions}

A new low-viscosity ionic liquid, [EMIm]TCB, has been used as an electrolyte to fabricate EDLCs. The ionic liquid possesses high ionic conductivity comparable to the conventional organic electrolyte, e.g. $\mathrm{TEMABF}_{4} / \mathrm{PC}$ etc. without any common solvent. The high specific capacitance, uncompromised performance and stability of the activated carbon/[EMIm]TCB interface against repeated charge/discharge cyclic operations demonstrate that ionic liquid, [EMIm]TCB, is a promising electrolyte for the fabrication of high performance EDLCs.

\section{Acknowledgements}

Authors acknowledge the financial support received from University of Delhi (11-17 Research Fund, 2010) and the Department of Science and Technology, Government of India (Sanction No. SR/S2/CMP-45/2005). One of the authors (GPP) is grateful to CSIR, New Delhi, for the award of a Research Associateship.

\section{References}

Armand M, Endres F, MacFarlane D R, Ohno H and Scrosati B 2009 Nat. Mater. 8621

Balducci A, Dugas R, Tabernaa P L, Simon P, Plee D, Mastragostino M and Passerini S 2007 J. Power Sources 165922
Conway B E 1999 Electrochemical supercapacitors-scientific, fundamentals and technological applications (New York: Kluwer Academic/Plenum Publishers)

Duong T Q 2003 Annual progress report for energy storage research and development (USA: FreedomCAR \& Vehicle Technologies Program, Energy Storage Research and Development, US Department of Energy) May 2004

Frackowiak E and Beguin F 2001 Carbon 39937

Handa N, Sugimoto T, Yamagata M, Kikuta M, Kono M and Ishikawa M 2008 J. Power Sources 1851585

Hashmi S A 2004 Natl Acad. Sci. Lett. 2727

Kötz R and Carlen M 2000 Electrochim. Acta 452483

Kuang D, Wang P, Ito S, Zakeeruddin S M and Grätzel M 2006 J. Am. Chem. Soc. 1287732

Lewandowski A and Galinski M 2004 J. Phys. Chem. Solids 65281 Lu W, Qu L, Henry K and Dai L 2009 J. Power Sources 1891270

McEwen A B, Ngo H L, LeCompte K and Goldman J L 1999 J. Electrochem. Soc. 1461687

Mysyk R, Raymundo-Piñero E, Anouti M, Lemordant D and Béguin F 2010 Electrochem. Commun. 12414

Ohno H (ed.) 2005 Electrochemical aspects of ionic liquids (New Jersey: Wiley Interscience)

Rotariu L, Zamfir L-G and Bala C 2010 Sens. Actuators B150 73

Sato T, Masuda G and Takagi K 2004 Electrochim. Acta 493603

Shi D, Cao Y, Pootrakulchote N, Yi Z, Xu M, Zakeeruddin S M, Grätzel M and Wang P 2008 J. Phys. Chem. C112 17478

Simon P and Gogotsi Y 2008 Nat. Mater. 7845

Sun G-H, Li K-X and Sun C-G 2006 J. Power Sources 1621444

Welz-Biermann U, Ignatyev N, Bernhardt E, Finze M and Willner H 2004 Patent WO 2004/072089 A1 (Germany: Merck GmbH, Darmstadt)

Wang K-P and Teng H 2007 J. Electrochem. Soc. 154 A993

Xu B, Wu F, Chen R, Cao G, Chen S, Wang G and Yang Y 2006 J. Power Sources 158773

Yan P-F, Yang M, Liu X-M, Wang C, Tan Z-C and Welz-Biermann U 2010 J. Chem. Thermodyn. 42817

Ye H, Huang J, Xu J J, Khalfan A and Greenbaum S G 2007 J. Electrochem. Soc. 154 A1048

Zhang L L and Zhao X S 2009 Chem. Soc. Rev. 382520 